\section{Effects of Surface Passivation on Top-Down ZnO Nanowire Transistors}

N.M.J. Ditshego, K. Sun, I. Zeimpekis, M.R.R.de Planque, P. Ashburn, H.M.H. Chong Nano Research Group, Electronics and Computer Science, University of Southampton, SO17 1BJ, UK Email: nmjd104@ecs.soton.ac.uk

Keywords—nanowire, remote plasma atomic layer deposition (RPALD), passivation, zinc oxide (ZnO)

Introduction: $\mathrm{ZnO}$ nanowire field effect transistors (NWFETs) can be fabricated using bottom-up or top-down approaches. Even though bottom-up devices may have better electrical characteristics; thei orientation, dimensions and addressability are difficult to achieve. Therefore, top-down fabrication method is favorable for producing controlled nanowire dimensions and location. In a back gate FET configuration, the nanowire channel is exposed to the atmospheric environment. The surface charges between insulator, air and nanowire channel can deplete the channel surface to lower the output drain current and affect the electrical performances such as threshold shift - making the device to behave like enhancement mode [2] This has also been observed in silicon-based nanowire FET [3]. It has been shown that passivation of ZnO TFT and bottom-up ZnO nanowire can improve electrical performance such as transconductance and mobility [4]. However, there is still little work done in the electrical performance of top-down space fabicition [4] space investigate the effect of surface passivation of $\mathrm{ZnO}$ nanowire channel with $\mathrm{Al}_{2} \mathrm{O}_{3}$ using atomic laye Fabricative

Fabrication: The ZnO NWFET is fabricated using our top-down spacer method [2], [3], which uses standard photolithography; remote plasma atomic layer deposition (RPALD) and anisotropic dry etch. RPALD process is conducted at 900 cycles, with each cycle consisting of 50 ms diethyl zinc (DEZ) precursor dose time, a $4 \mathrm{~s}$ Ar purge , a $2.65 \mathrm{~s}$ oxygen plasma, and a final $4 \mathrm{~s}$ Ar purge. The deposition temperature is done at $190{ }^{\circ} \mathrm{C}$ and the RF power and pressure were set at $100 \mathrm{~W}$ and 15 mtorr respectively. The deposited $\mathrm{ZnO}$ layer thickness is $76 \mathrm{~nm}$ and was measured using an ellipsometer. The natural n-type carrier concentration is $1 \times 10^{18} \mathrm{~cm}^{-3}$ and measured using a Hall Effect system. We use anisotropic inductively coupled plasma (ICP) etcher and $\mathrm{CHF}_{3}$ gas chemistry to remove the $\mathrm{ZnO}$ layer. Figure 1 (a) shows the top view microscope image of the ZnO NWFET with the source drain connection; and Figure 1(b) shows the cross section scanning electron micrograph of the $\mathrm{ZnO}$ nanowire. Then thermal ALD is used to deposit a layer of $18 \mathrm{~nm}$ thick $\mathrm{Al}_{2} \mathrm{O}_{3}$ over the $\mathrm{ZnO}$ nanowires at temperature of $200{ }^{\circ} \mathrm{C}$. The aluminum

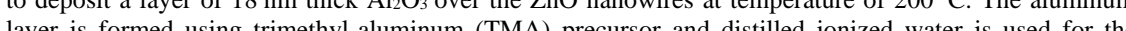
layer is fome us. oxidation process. Finally, aluminum lift-off process is used to form ohmic contact at the source and drain region. The fabicated NWFTs have channel lengh of $8.6 \mu \mathrm{m}$, thickness of $80 \mathrm{~nm}$ and width of $20 \mathrm{~nm}$ The electrical $\mathrm{I}-\mathrm{V}$ characterization of the ZnO NWFETs is done using Agilent B1500A semiconductor parametric analyzer

Results: Figure 2(a) shows the $I_{d} V_{d}$ characteristics for un-passivated device with output drain current $I_{d}=0.18 \mu \mathrm{A}$; whereas the passivated device has $I_{d}=0.4 \mu \mathrm{A}$ when mesured at $V_{d}=1 \mathrm{~V}$ and $V_{g}=20 \mathrm{~V}$. Figure 2(b) shows that threshold voltage shift before and after passivation from $\mathrm{V}_{\mathrm{T}}=6.5 \mathrm{~V}$ to $\mathrm{V}_{\mathrm{T}}=-10 \mathrm{~V}$. The unpassivated NWFET initially exhibits enhancement mode operation and after passivation it reverts to the expected depletion mode, since the $\mathrm{ZnO}$-channel has a concentration of $1 \times 10^{18} \mathrm{~cm}^{-3}$. The $\mathrm{I}_{\mathrm{d}}$ increase after passivation is confirmed analytically using the linear region equation $I_{d}=C_{N W} \mu_{F E}\left(V_{g}-V_{T}\right) V_{D} / L^{2}$ [5], where the $\left(C_{N W}=0.92 \mathrm{fF}\right)$ is considered to be the capacitance of the dual nanowire, $\mathrm{L}$ is the length of the channel and $\mu_{F E}$ is the field effect mobility. The extracted field effect mobility from the trancoly transivation pross bas imp papivion pocted depletion mode operation. Futh work will includes effect of passivation layer against threshold voltag and drain curent ouput and investigato w roughness. The top-down passivated ZnO NWFET has the potential application biosensing application.
Acknowledgement: N.M.J. Ditshego would like to thank the Botswana International University of Science and Technology for supporting his doctoral studies and the Southampton Nanofabrication Centre for the experimental work

References:

[1] R. Ahmad, N. Tripathy, and Y.-B. Hahn, Biosens. Bioelectron., vol. 45, pp. 281-6, Jul. 2013.

[2] S. M. Sultan ,K.Sun, O.D.Clark, T.B.Masaud, Q.Fang, R.Gunn, J.Partridge, M.W.Allen, P.Ashburn, and H.M.H.Chong, IEEE Electron. Dev. Lett., vol. 33, no. 2, pp. 203-205, Jul. 2012.

[3] M. M. A. Hakim, M. Lombardini, K. Sun, F. Giustiniano, P. L. Roach, D. E. Davies, P. H. Howarth, M. R. R. de Planque, H. Morgan, and P. Ashburn, Nano Lett., vol. 12, no. 4, pp. 1868-72, Apr. 2012.

[4] K. Keem, D. Jeong, S. Kim, and M. Lee, Nano, vol. 6, no. 7, p. 5 pp.-5 pp.5 pp., May 2006.

[5] S. M. Sze and K. K. Ng, Physics of Semiconductor Devices, 6, 1, Wiley-Interscience, 2007.

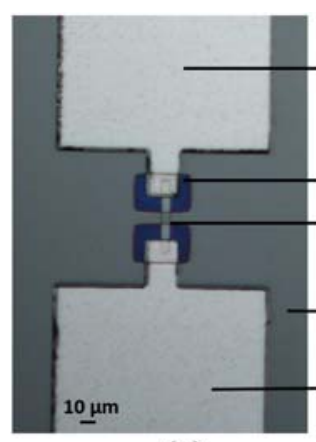

(a)

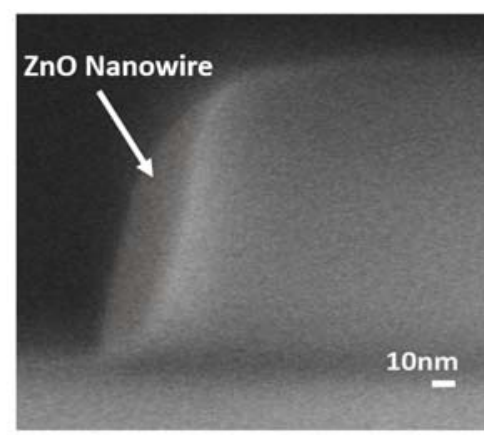

(b)
Figure 1: NWFET device structure (a) schematic of fabricated device (b) Cross-sectional SEM image of $\mathrm{ZnO}$ nanowire.
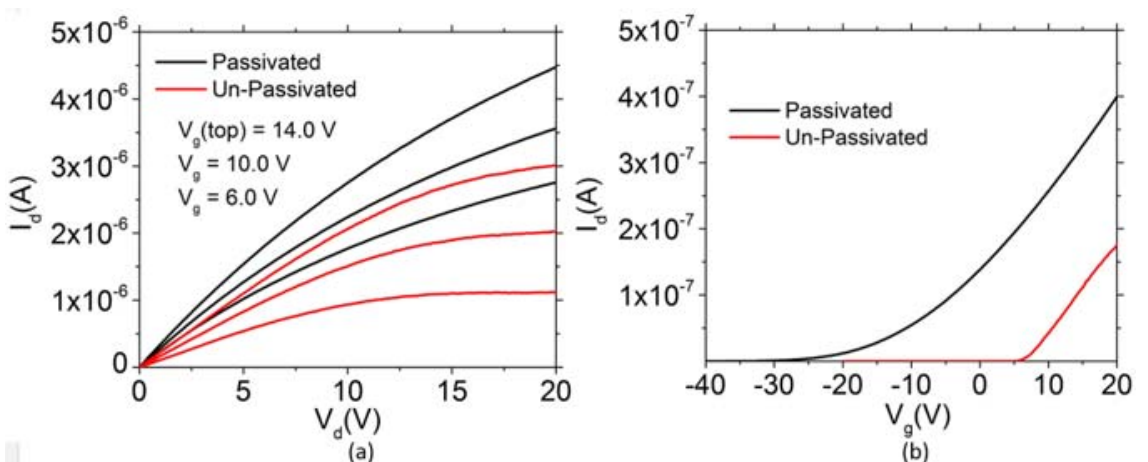

Figure 2: Passivated verses un-passivated (a) $\mathrm{I}_{d} \mathrm{~V}_{d}$ (b) $\mathrm{I}_{d} \mathrm{~V}_{\mathrm{g}}$ characteristics with $\mathrm{V}_{\mathrm{d}}=1.0 \mathrm{~V}$. 